\title{
Mercado profissional para a área de energia e eficiência energética no Brasil
}

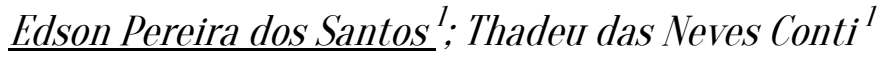 \\ 凹epsantos@sp.senai.br
}

1. IPEN/USP Instituto de Pesquisas Energéticas e Nucleares, Avenida Lineu Prestes, 2242, São Paulo, Brasil.

Histórico do Artigo:

Recebido: 31 de março de 2017
Aceito: 21 de junho de 2017

Publicado: 5 de janeiro de 2018

Resumo: Com o crescente aumento da participação de fontes renováveis de geração energia em nossa matriz energética e a grande preocupação das organizações com a gestão de energia, cada vez mais, é evidenciado a necessidade de se promover programas de formação profissional que garantam a mão obra especializada para os profissionais envolvidos nestes processos. Vários aspectos são relevantes, entre esses é possível identificar a falta de know-how para uso de novas tecnologias, infraestrutura das instituições de ensino, formação, padronização e projetos para certificação de pessoas, para que assim sejam garantidos os resultados dos projetos desenvolvidos nas áreas de energia e eficiência energética. Neste trabalho é apresentado o estudo atual dos principais gargalos na formação destes profissionais, bem como um cenário geral das ações educacionais desenvolvidas pela iniciativa pública e privada, juntamente com os demais atores envolvidos, com objetivo de reduzir a carência técnica dos profissionais e a garantia dos benefícios que estas novas tecnologias podem trazer para a economia, sociedade, meio ambiente e para o desenvolvimento do país.

Palavras-chave: Mão de obra, Know-how, Formação profissional.

\section{Professional market for the area of energy and energy efficiency in Brazil}

\begin{abstract}
With the increasing share of renewable energy sources in our energy mix and the great concern of organizations with energy management, it is evidenced the need to promote vocational training programs which ensure the specialized labor for the professionals involved in these processes. Several aspects are relevant, and among these it is possible to identify a lack of knowledge in the use of modern technologies, deficit of infrastructure for educational and training institutions, insufficient standardization, and a lack of projects for accreditation of workforce, so that the results of the projects developed in the areas energy and energy efficiency are guaranteed. In this paper, the current study of the major bottlenecks in the formation of these professionals is presented, as well as an overview of the educational actions developed by public and private initiatives, along with the rest of the actors involved, whose goal is to reduce the lack of technical knowledge of professionals and to guarantee the benefits that these recent technologies can bring to the economy, society, environment and to the development of the country.
\end{abstract}

Keywords: Labor, Technical knowledge, Professional training. 


\section{Mercado profesional para el área de energia y eficiencia energética en Brasil}

Resumen: Dada la creciente participación de las fuentes renovables de generación de energía en nuestra matriz energética y la gran preocupación de las organizaciones sobre la gestión de la energía, se evidencia la necesidad de promover programas de formación profesional para garantizar la mano de obra especializada para los profesionales involucrados en estos procesos. Varios aspectos son relevantes, entre estos es posible identificar la falta de conocimientos técnicos para utilizar las nuevas tecnologías, carencia de infraestructura para instituciones educativas y de formación, insuficiencias en normalización, y falta de proyectos para la certificación de profesionales, para que así sean garantizados los resultados de los proyectos desarrollados en las áreas de energía y de eficiencia energética. En este trabajo se presenta un estudio actual de los principales cuellos de botella en la formación de estos profesionales, así como una visión general de las acciones educativas desarrolladas por el sector público y privado, junto con otros actores involucrados, con el objetivo de reducirla carencia de conocimiento técnico de los profesionales y de garantizar los beneficios que estas nuevas tecnologías pueden aportar a la economía, a la sociedad, al medio ambiente y para el desarrollo del país.

Palabras clave: Mano de obra, Conocimiento técnico, Formación profesional.

\section{INTRODUÇÃ0}

A globalização do mercado e a competitividade observada na sociedade atual forçam as instituições e empresas a possuírem um sistema produtivo e de consumo cada vez mais eficiente, visando uma melhora nos processos e, consequentemente, na qualidade dos produtos, aliado à redução dos custos operacionais.

Um dos fatores que agregam valor ao processo sem dúvida é a utilização das diferentes fontes de energia (eletricidade, gás, água, etc.), empregando conceitos de "Eficiência Energética” e o uso de Fontes de Energia Renováveis, o que busca melhorar a relação entre a energia consumida e a produção (custo específico do produto). 0 resultado desejado é reduzir o consumo de energia mantendo ou aumentando a produtividade, além disso, é esperado que a demanda por esta energia, já utilizada de maneira eficiente, seja obtida como garantia à sustentabilidade do planeta, ou seja, uma geração de energia de baixo carbono que emita cada vez menos gases de efeito estufa (GEE), contribuindo assim para ações de sustentabilidade.

A relevância da energia como insumo para os processos produtivos é bastante conhecida, sem energia nada pode ser realizado, transportado ou processado. A disponibilidade, custo e qualidade da energia são fatores determinantes para competitividade do setor produtivo. Sabe-se que boa parte da energia entregue às unidades produtivas, provém de fontes diversas de geração (hidráulica, térmica, eólica, nuclear, solar, biomassa, etc.), essas, 
geralmente desperdiçadas ou usadas com baixa eficiência, sendo igualmente reconhecida a necessidade de melhorar o rendimento dos processos energéticos no contexto industrial, proporcionando vantagens econômicas e ambientais.

Na busca da segurança energética, destaca-se a opção pela geração autônoma e aplicação de ações de eficiência energética como fator de racionalidade na oferta e uso de energia. Com o aumento do custo da eletricidade e da emissão de gases causadores do efeito estufa, ações voltadas para a racionalização tornam-se ainda mais atrativas.

0 estudo aqui apresentado consiste em extrair informações do mercado de energia demonstrando os principais desafios, preocupações e gargalos que envolvem a formação dos profissionais que atuam neste cenário, ações e iniciativas das instituições de ensino e formação profissional, que possuem o compromisso de atender a formação especifica desta mão de obra e por fim, a demanda existente por profissionais com competências específicas nas organizações e consumidores finais.

0 Centro de Engenharia Nuclear - CEN pelo Instituto de Pesquisas Energéticas e Nucleares - IPEN/USP juntamente com o SENAI-SP, possuem linhas de pesquisas específicas que consistem no desenvolvimento de estudos, ressaltando a importância do uso e aplicação de Mecanismos de Desenvolvimento Limpo (MDL), para a área de energia que fomentam a utilização destas ações. A disseminação deste trabalho contribuirá significativamente para as pesquisas já existentes nestas organizações.

\section{MATERIAL E MÉTODOS}

A primeira etapa dessa pesquisa consiste em obter uma base de dados confiável para análise, com isso temos como base, a coleta de informações feitas a partir de fontes oficiais, tais como:

- Balanço Energético Nacional

- $\quad$ IRENA - Agência Internacional para as Energias Renováveis

- $\quad$ EPE - Empresas de Pesquisas Energética

- $\quad$ Indicadores de Economia de Energia 
- Dados de Serviços Educacionais do Estado de São Paulo

Estabelecendo uma orientação para a definição de prioridades para a implementação de produtos educacionais na área de Energia e Eficiência Energética, a primeira prioridade é o desenvolvimento de cursos que tenham a capacidade de oferecer as competências destinadas a formação de instaladores, técnicos, especialistas, engenheiros e gestores de processo. A segunda prioridade é desenvolver treinamentos específicos para o corpo técnico/docente e dos profissionais envolvidos neste processo. Na sequência, faz-se necessário possuir uma infraestrutura adequada com laboratórios e ambientes didáticos apropriados, garantindo as condições ideais para o desenvolvimento de estratégias de ensino adequadas contendo atividades práticas e teóricas, capazes de propiciar um cenário de formação completo aos indivíduos.

Visando uma assertividade nas ofertas dos programas de formação profissional, é necessário realizar um preciso levantamento de dados para entender a demanda de mercado, identificando as principais carências de mão de obra, características e atividades da mesorregião, uma elaboração de cursos deve ser realizada e analisada por um conjunto de atores diversos, que representam vários setores, entre eles: as indústrias, sindicatos, associações, instituições de ensino e representantes do poder público e da comunidade.

Como base neste estudo,foram obtidos os levantamentos feitos pelas associações dos diferentes setores, exemplo: a ABESOLAR (Associação Brasileira de Energia Solar Fotovoltaica), ABEEÓLICA (Associação Brasileira de Energia Eólica), ABESCO (Associação Brasileira das Empresas de Serviços de Conservação de Energia), IRENA (Agência Internacional para as Energias Renováveis) entre outras. Estas organizações, realizam estudos de oportunidades e de prospecção, fornecendo um panorama promissor para o aumento das instalações envolvendo geração de energia e eficiência energética e, como consequência nas oportunidades de trabalhos nos respectivos setores.

Os dados fornecidos pela International Renewable Energy Agency (Irena) - Agência Internacional de Energia Renovável, na revisão anual 2016, Energia Renovável e Empregos, estima-se que a taxa global de vagas de empregos relacionados à energia renovável aumentou 5\% em 2015, atingindo 8,1 milhões de pessoas, enquanto o número de vagas de emprego relacionadas aos demais setores de energia encolheu em comparação aos anos anteriores. Os países com o maior número de vagas de empregos relacionados a energias renováveis foram 
China, Brasil, Estados Unidos, Índia, Japão e Alemanha, resultado de quadros políticos favoráveis, mudanças regionais na implantação de sistemas de energias renováveis, bem como aumento da produtividade industrial. A seguir são apresentadas as quantidades de vagas na área de energia renovável e as diferentes tecnologias empregadas.

Conforme a transição da matriz energética se acelera, as vagas de emprego relacionadas a energias renováveis continuam crescendo, este nível de crescimento está propenso a diminuir na medida em que a indústria amadurece e a produtividade do trabalho se desenvolve. As estimativas do IRENA apontam que a duplicação da cota de energias renováveis na matriz energética global, resultaria em mais de 24 milhões de empregos em todo o mundo em 2030 (IRENA, 2016), porém, esse cenário favorável exige quadros políticos estáveis e previsíveis que incentivem a implantação de novas instalações, estimulem os investimentos em indústrias locais, reforcem as capacidades, promovam a educação e formação profissional. Na figura 1, é demonstrado o número de vagas de empregos relacionado com a área de energias renováveis em 2015.

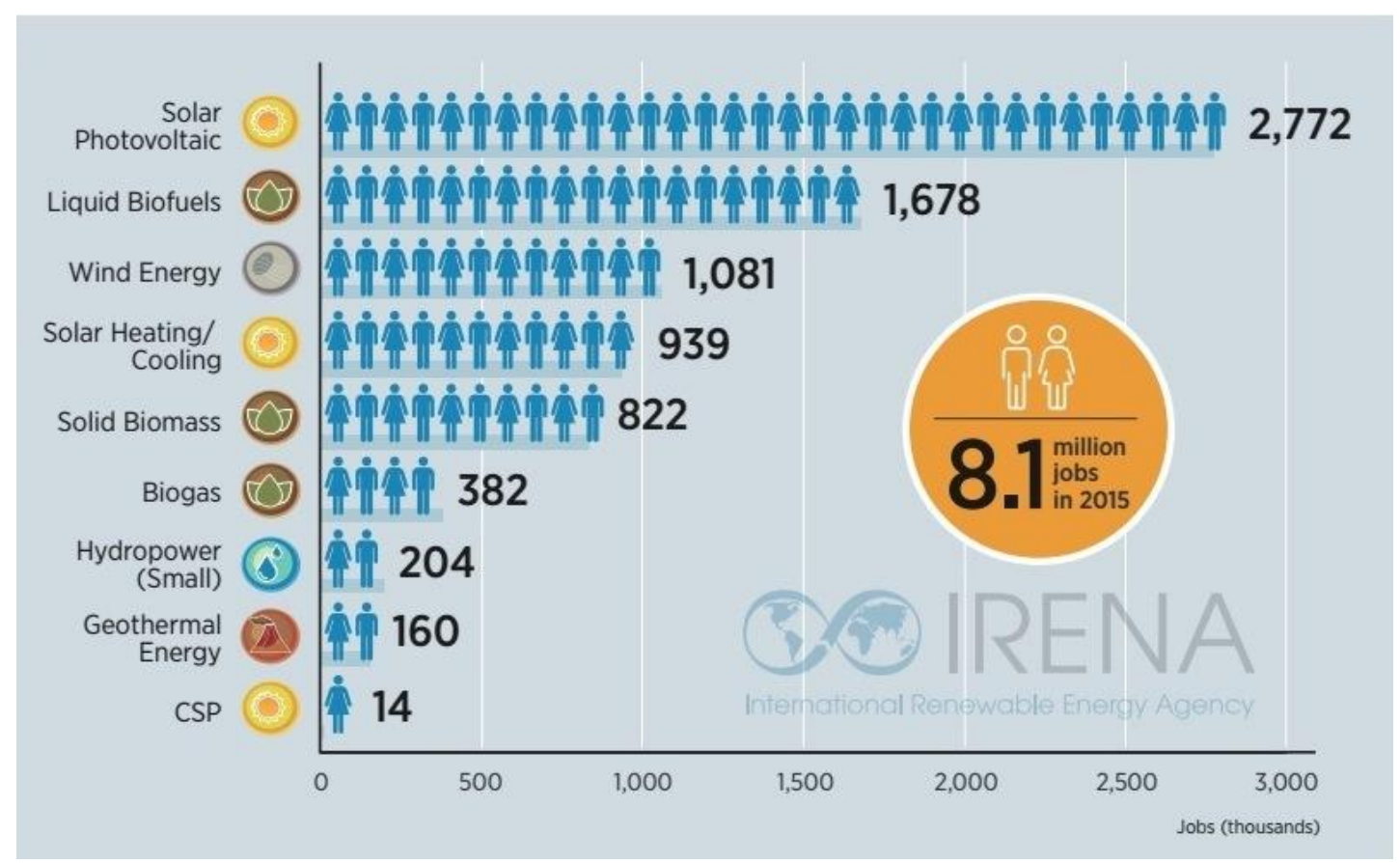

Figura 1. Vagas de emprego relacionadas à energia renovável por tecnologia Fonte: IRENA, 2016. 


\section{Energia Solar Fotovoltaica}

A energia solar é a que mais cresce na matriz mundial, no Brasil, até 2050, 18\% dos domicílios brasileiros poderão contar com geração fotovoltaica, segundo projeções da Empresa de Pesquisa Energética (EPE). Atualmente, no país são mais de 2.500 sistemas de energia fotovoltaica conectados à rede elétrica, com um ótimo potencial de geração devido a excelente incidência solar,fazendo com que esta tecnologia seja altamente expandida. Isso é o que foi demonstrado no histórico dos últimos dois anos com um crescimento de $300 \%$.

Para geração de energia fotovoltaica, um fator importante é que para cada megawatt instalado, são gerados entre 25 a 30 empregos diretos, distribuídos em instaladores de painéis, projetistas, fabricantes e montadores de sistemas.

Uma maior disseminação da tecnologia junto a sociedade, com a apresentação de seus benefícios e oportunidades de economia, pode ser um fator decisivo para uma maior participação desta fonte na matriz elétrica. As condições climáticas e geográficas são altamente favoráveis,podendo assim obter energia praticamente o ano inteiro.

As recentes reduções nos custos dos sistemas de energia solar fotovoltaica, têm impulsionado a implantação dessa tecnologia tanto em usinas de geração quanto em geração distribuída. Trata-se de um reforço na criação de emprego, uma vez que globalmente, em 2015, as instalações solares fotovoltaicas foram $20 \%$ maiores que no ano anterior, com a China, o Japão e os Estados Unidos na liderança.

Consequentemente, a energia solar fotovoltaica foi novamente a fonte renovável que mais empregou os profissionais, com 2,8 milhões de empregos em 2015, um aumento de $11 \%$ em relação ao ano anterior. A China ainda é considerada a maior empregadora de profissionais dessa área, com 1,7 milhões de postos de trabalho em 2015, fato relacionado à sua liderança incontestável na fabricação e instalação dessa tecnologia. No Japão, o emprego relacionado à energia solar fotovoltaica cresceu $28 \%$, atingindo 377.100 postos de trabalho em 2014, informações do ano mais recente disponível, em parte como consequência de tarifas feed-in atraentes (JPEA, 2016). Nos Estados Unidos, as altas taxas de implantação levaram a criação de emprego a níveis recordes. Em contraste, o emprego de energia solar fotovoltaica na União Europeia (UE) caiu 13\% em 2014, principalmente devido a uma redução na produção, na figura 2 é apresentado a estimativa de empregos da área de energia renovável dividida por setor e tecnologia. 


\begin{tabular}{|c|c|c|c|c|c|c|c|c|c|c|}
\hline & \multirow[t]{2}{*}{ World } & \multirow[b]{2}{*}{ China } & \multirow[b]{2}{*}{ Brazil } & \multirow[b]{2}{*}{$\begin{array}{l}\text { United } \\
\text { States }\end{array}$} & \multirow[b]{2}{*}{ India } & \multirow[b]{2}{*}{ Japan } & \multirow[b]{2}{*}{$\begin{array}{l}\text { Bang- } \\
\text { ladesh }\end{array}$} & \multicolumn{3}{|c|}{ European Union' } \\
\hline & & & & & & & & Germany & France & $\begin{array}{l}\text { Rest } \\
\text { of EU }\end{array}$ \\
\hline $\begin{array}{r}\text { Solar } \\
\text { Photovoltaic }\end{array}$ & 2.772 & 1.652 & 4 & 194 & 103 & 377 & 127 & 38 & 21 & 84 \\
\hline $\begin{array}{r}\text { Liquid } \\
\text { Biofuels }\end{array}$ & 1.678 & 71 & $821^{c}$ & $277^{t}$ & 35 & 3 & & 23 & 35 & 47 \\
\hline $\begin{array}{l}\text { Wind } \\
\text { Power }\end{array}$ & 1.081 & 507 & 41 & 88 & 48 & 5 & 0.1 & 149 & 20 & 162 \\
\hline $\begin{array}{r}\text { Solar } \\
\text { Heating/ } \\
\text { Cooling }\end{array}$ & 939 & 743 & $41^{d}$ & 10 & 75 & 0.7 & & 10 & 6 & 19 \\
\hline $\begin{array}{r}\text { Solid } \\
\text { Biomass }^{0,9}\end{array}$ & 822 & 241 & & $152^{\circ}$ & 58 & wable & Energy $\mathrm{A}$ & 49 & 48 & 214 \\
\hline Biogas & 382 & 209 & & & 85 & & 9 & 48 & 4 & 14 \\
\hline $\begin{array}{l}\text { Hydropower } \\
\text { (Small) }^{\mathrm{b}}\end{array}$ & 204 & 100 & 12 & 8 & 12 & & 5 & 12 & 4 & 31 \\
\hline $\begin{array}{r}\text { Geothermal } \\
\text { energy }\end{array}$ & 160 & & & 35 & & 2 & & 17 & 31 & 55 \\
\hline CSP & 14 & & & 4 & & & & 0.7 & & 5 \\
\hline Total & $8,079^{\circ}$ & 3.523 & 918 & 769 & 416 & 388 & 141 & $355^{i}$ & 170 & $644^{k}$ \\
\hline
\end{tabular}

Figura 2. Trincheira Vagas de emprego relacionado à energia renovável por país Fonte: IRENA, 2016.

No Brasil a utilização da energia solar acontece há aproximadamente três décadas, iniciado com sistemas de pequeno porte, os profissionais atuantes eram eletricistas sem total domínio da tecnologia e dos sistemas envolvidos, mas, apesar do longo período, ainda hoje, há poucos profissionais com conhecimentos específicos e que conheçam as particularidades e exigências técnicas dos sistemas. Há uma grande preocupação com a segurança das instalações e também com a garantia técnica e econômica das instalações de energia solar fotovoltaica, para isso, padrões de ligações, procedimentos e normas técnicas são constantemente elaboradas a fim de garantir os resultados dos investimentos.

Segundo especialista Roberto Zilles do IEE-USP, a maioria destes profissionais detém o conhecimento da área elétrica, muitos com certificação de nível médio e outros com a formação de engenheiros eletricistas, mas, em seus respectivos currículos, são escassas as experiências relacionadas com as particularidades das instalações fotovoltaicas.

0 que se espera do mercado é uma forte exigência na qualidade da formação de mão de obra destes profissionais, o que pode ser conseguido por várias iniciativas, como por exemplo, um rigoroso processo de certificação de instaladores, realizados por entidades conceituadas e 
isentas, estes exames atestariam as capacidades técnicas dos profissionais,por meio de testes práticos e teóricos. Outra iniciativa é a inserção do conteúdo específico sobre sistema solar fotovoltaico nos cursos técnicos e de graduação no Brasil.

Várias instituições de ensino e formação profissional, já oferecem itinerários específicos para a formação de profissional de energia solar fotovoltaica, dentre essas podemos citar a UNICAMP (Universidade Estadual de Campinas-SP) e o SENAI-SP que dispõe de uma estrutura de formação profissional, que abrangem desde os conceitos e aplicações iniciais, instalações de sistemas e também a capacitação de projetistas e dimensionadores de sistemas.

\section{Geração Eólica}

Segundo a ABEEólica, a geração eólica no Brasil é atribuída atualmente as 400 usinas instaladas, a produção de eletricidade a partir desta fonte em 2015 alcançou 21.626 GWh, crescimento de 77,1\% ultrapassando assim a geração nuclear em 2015. A potência eólica atingiu 9,96 GW em agosto de 2016, a figura 3, demostra a expansão e a participação dessa fonte na matriz para $6,8 \%$.

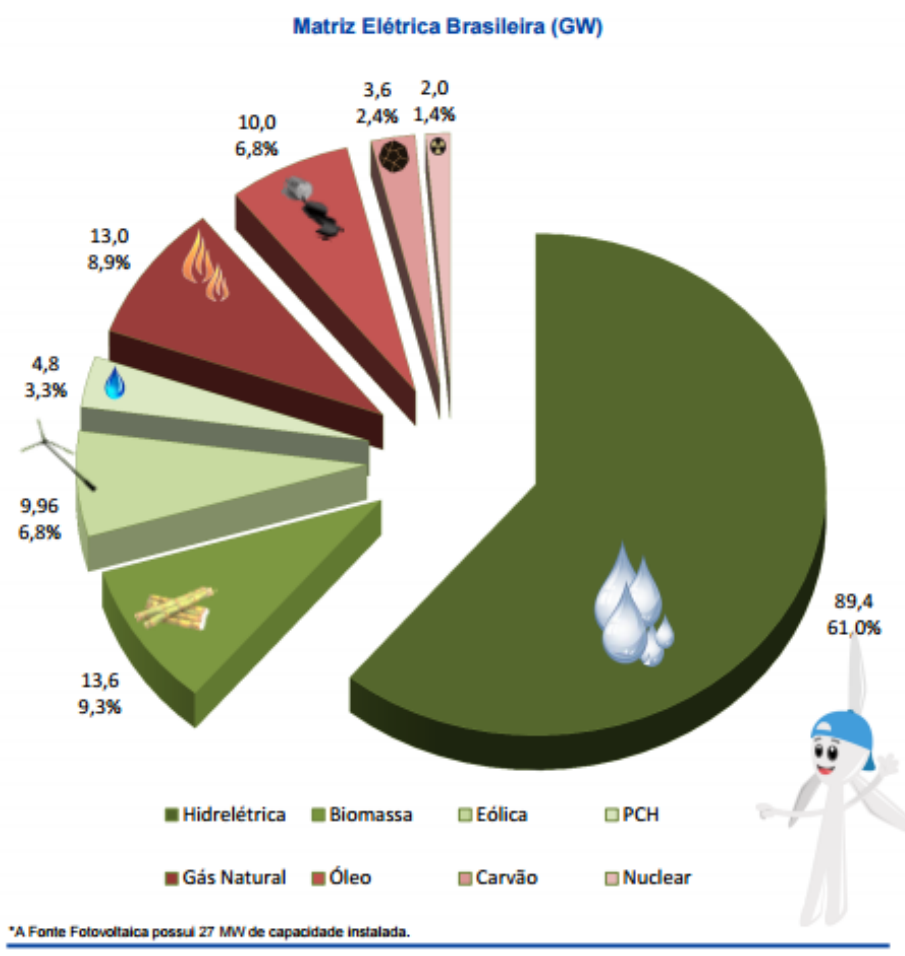

Figura 3. Matriz Elétrica Brasileira 
Fonte: ABEEólica,2016.

A capacidade instalada no Brasil sofreu um crescimento significativo nos últimos anos, por questões de aspectos técnicos, econômicos e também políticos, este tipo de geração cada vez mais aumenta sua representação em nossa matriz. A figura 4 demonstra essa evolução e caracteriza uma prospeç̧ão de crescimento de $80 \%$ na produção de aproximadamente 18,42 GW até 2020.

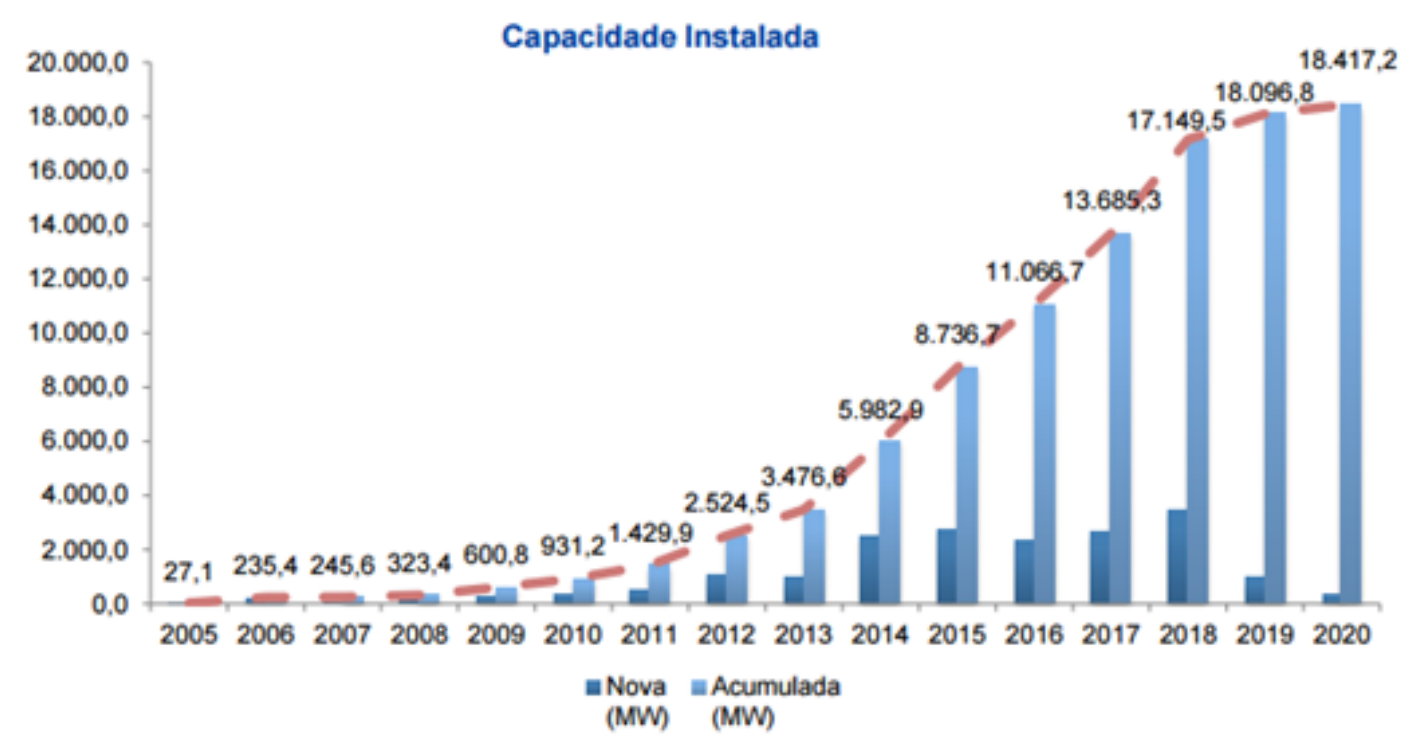

Figura 4. Evolução da Capacidade Instalação Eólica Fonte: ABEEólica/ANEEL,2016.

Para que seja desenvolvido o cenário promissor, uma forte indústria deve ser criada, fornecendo soluções, serviços e componentes para os diferentes sistemas que envolvem o setor.

Como acontece em alguns setores do mercado, o seguimento de Energia Renovável também enfrenta dificuldades para encontrar profissionais qualificados. Um estudo da Agência Internacional de Energia Renovável (IRENA), informou em 2014 que o Brasil é o segundo país que mais cria vagas na área de energia limpa, aproximadamente 900.000 pessoas, somente perdendo para a China. 0 setor de energia limpa que mais emprega no país é da bioenergia seguido pela eólica. 
A energia eólica está em forte crescimento, 2,3 mil megawatts/ano, diferente de outros setores da economia, apresenta uma dificuldade na obtenção de mão de obra qualificada e como o setor ainda é considerado novo no país, não possuímos muitos profissionais com background, considerando o rápido crescimento do número das instalações no Brasil.

Existe uma relação direta entre a utilização de mão de obra e a energia instalada, na energia eólica são criados 15 novos postos de trabalhos para cada 1MW. Atualmente, o setor emprega 32 mil pessoas e como há uma perspectiva de aumento nos números de instalações, a projeção é de um potencial de 280 mil empregos diretos e indiretos até 2020.

Algumas importantes empresas optam pela contratação de profissionais vindo do exterior, assumindo um importante papel na disseminação do conhecimento e na transferência de tecnologia. É importante citar também, atuação das cooperações técnicas entre as nações, que desempenham um relevante papel na formação e capacitação técnica dos profissionais no Brasil, entres essas, podemos mencionar a forte atuação da Agencia de Cooperação Internacional da Alemanha (Deutsche Gesellschaftfür Internationale Zusammenarbeit - GIZ), responsável por vários programas na área de energia no país.

Com o intuito de preparar a mão de obra para a área de energia eólica, algumas instituições de ensino e centros de formação profissional especializados, também desenvolvem programas de capacitações que visam atender essas demandas, entre as universidades podemos citar, a Universidade Federal do Ceará (UFC), UNIPAMPA - Universidade Federal de Pernambuco, Universidade Federal da Fronteira Sul (UFFS) em Santa Catarina.No âmbito das instituições de formação profissional, predomina o trabalho do SENAI-SP, que desenvolve o Curso Técnico em Sistemas de Energia Renovável, profissional este, que além de possuir as competências de gestão de energia nas organizações, também desenvolve uma atuação direta na utilização de energias renováveis do tipo eólica, solar fotovoltaica, energia hidráulica e biomassa.

\section{Eficiência Energética}

Para um melhor planejamento dos sistemas de fornecimento de energia, são levantadas as incertezas e os desafios envolvendo o aumento do consumo. Várias ações e políticas são imprescindíveis para que se possa garantir a estabilidade técnica e segurança 
energética para o atendimento a essa demanda, os aspectos quantitativos e qualitativos são associados e identificados, também a inserção de novos sistemas e tecnologias são previstos para organismos responsáveis para planejar o atendimento do fornecimento, definindo uma trajetória assertiva de curto e longo prazo, cuja análise considera alguns fatores importante como:

- Aplicação de eficiência energética no consumidor final de energia;

- Expansão da Geração Distribuída;

- Inserção de novas tecnologias em setores da indústria, transporte e residenciais;

- Aumento incorporação de novos consumidores neste horizonte (50\% até 2050);

- Evolução das edificações brasileiras;

- A competitividade entre os diferentes energéticos.

Algumas das diretrizes de expansão do setor são previstas e apontadas nos relatórios da EPE Empresa de Pesquisas Energéticas, apresentadas em balanços, figura 5, e levantamentos periódicos que visam definir estratégias para o atendimento do setor energético brasileiro. 


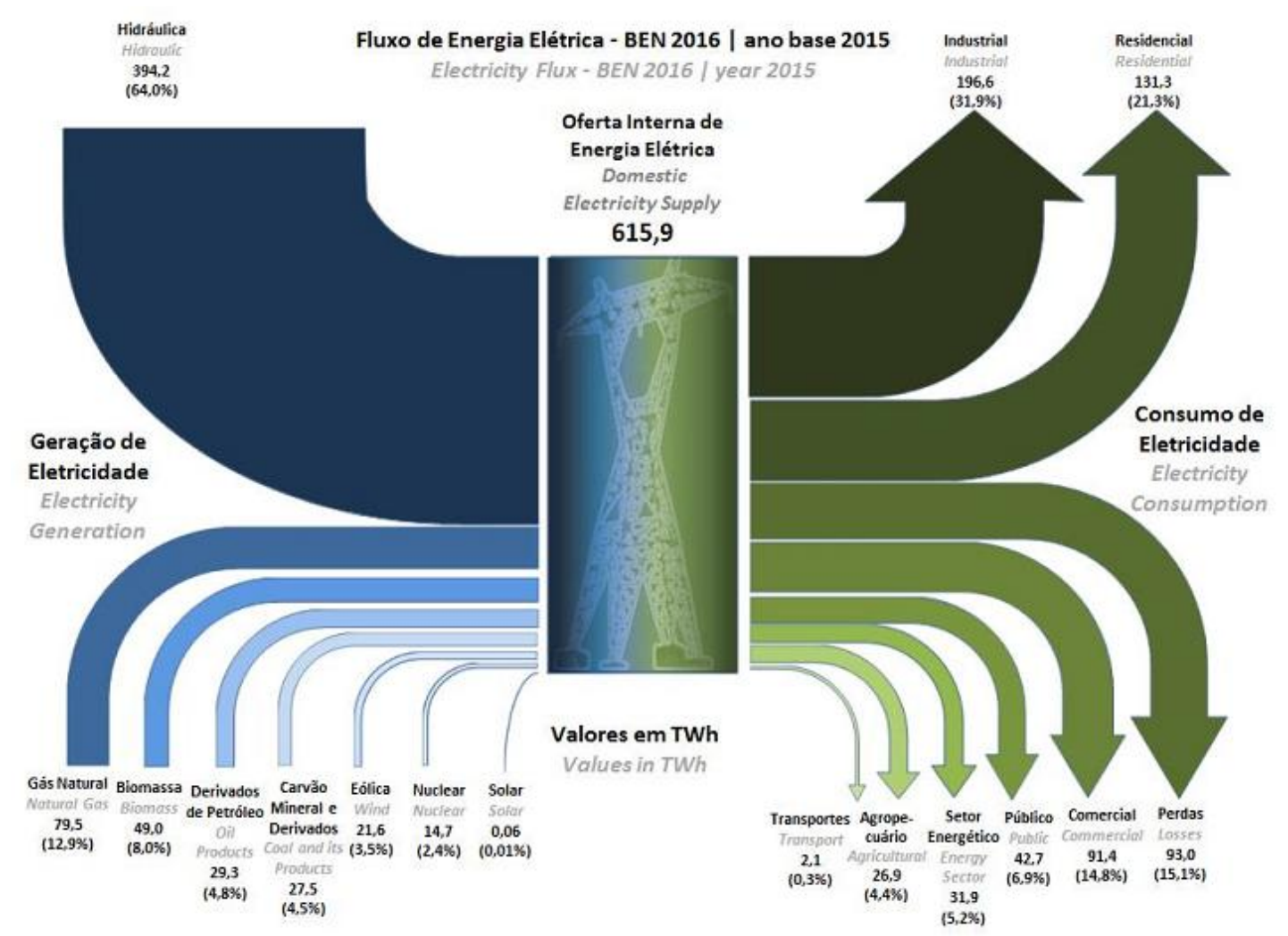

Figura 5. Evolução Fluxo de Energia Elétrica Fonte: BEN 2016 / ano base 2015.

Várias ações e políticas são inseridas no mercado para promoção da eficiência energética, certificações de equipamentos e empreendimentos, leis de controle e fundos de financiamentos específicos, todas elas com o objetivo de fomentar oportunidades e estimular as implementações de uso e consumo racional da energia. Segundo a EPE, a projeção da demanda de energia elétrica ao longo do período de 2013-2050 soma ganhos com eficiência energética de $17 \%$ do consumo total de eletricidade, o que significa uma redução de 43GW médio, aproximadamente cinco vezes a usina de Itaipu. (EPE, 2016), com isso um cenário de mudanças expressivas deve acontecer.

Profissionais de diferentes áreas e com conhecimentos multidisciplinares estão cada mais presentes em projetos e ações de eficiência energética. Nas organizações atuais, são esperados e atribuídos múltiplas competências aos gestores de energia, cuja responsabilidade é gerenciar os insumos energéticos envolvidos nos processos produtivos e nas instalações industriais, sempre com vistas à melhoria contínua e no atendimento das metas acordados pela alta direção da empresa. 
Além destes atores de nível de gestão, também é esperado dos profissionais, competências técnicas especificas para os setores de uso final de energia, como por exemplo, especialistas em sistema de climatização e refrigeração, motores e acionamento, sistemas de iluminação, fornecimento de vapor e ar comprimido. É solicitado principalmente um profissional com visão sistêmica para o processo produtivo, este último, com a responsabilidade de integrar-se entre as áreas de utilidades e produção, identificando o melhor desempenho energético para cada processo e também para cada tecnologia instalada.

Instituições de ensino profissional vêm ao longo do tempo oferecendo formações e capacitações específicas para atendimento desta demanda. Percebe-se que algumas competências são muitas vezes adquiridas na vivência e experiência profissional do indivíduo, mas sem uma metodologia concreta e sedimentada pode comprometer a garantia da segurança no alcance dos resultados esperados, como por exemplo, tempo de retorno, total de economia, total de investimento, mitigação de $\mathrm{CO}_{2}$, etc.

Com o objetivo de contribuir para o sucesso destas ações promovendo o aumento da garantia dos projetos e resultados como viabilidades técnicas e econômicas, são oferecidas aos profissionais do setor, formações de aperfeiçoamento na área de eficiência energética, projetos de iluminação, eficiência energética para climatização, gerenciamento de energia, formação para SGE baseado na NBR ISO 50.001, entre outros. Além da formação continuada, também há programas com a inserção de disciplinas de Eficiência Energética nos cursos técnicos, o intuito desta iniciativa é preparar o profissional técnico antes da entrada do mercado de trabalho.

Para atender ao público com formação no ensino superior, existem programas de pósgraduação para gestão de energia, cursos de eficiência energética voltada à indústria e a edificações, programas entre outros como o do SENAI-SP que realizam dentro da formação de especialização, visitas técnicas internacionais, exemplo para a Alemanha, o que proporciona ao aluno uma transferência de conhecimento única e valiosa, uma vez que são previstas visitas em institutos de pesquisas, universidades e também e empresas que são modelos em eficiência energética.

Algumas organizações são citadas e referenciadas no mercado como excelência em ensino e formação profissional para os níveis técnicos, superiores e de pós-graduação, entre essas estão o Centro Paula Souza, USP, UNESP, ISITEC e o SENAI, todos esses atores com 0 
importante papel e responsabilidade de promover iniciativas para a formação e capacitação profissional, desencadeando um cenário positivo e sólido, com a garantia técnica dos profissionais atuantes nas áreas do setor energético.

\section{RESULTADOS E DISCUSSÃ0}

Durante o desenvolvimento desta pesquisa verificou-se uma grande quantidade de informações em artigos, livros, teses e sítios na internet sobre a eficiência energética e gargalos na formação e capacitação destes profissionais. Observou-se, porém, uma escassez de iniciativas concretas principalmente do poder público, visto que os índices norteadores apontam um aumento significativo do mercado de energia renovável e de eficiência energética.

Aplica-se como base o importante relatório do Renewable Energy and Jobs - Annual Review 2016, divulgado pela Agência Internacional de Energias Renováveis (IRENA), que apresenta um cenário bastante positivo e promissor para o segmento de energia, se tornando mais um motivo de estímulo do setor energético e construção sustentável, o setor de energias renováveis junto com o de eficiência energética, está em alto crescimento em todo 0 mundo, juntamente com este aumento acontece a geração de empregos específicos para a área de energia.

0 estudo faz uma análise da situação do mercado de trabalho no âmbito de energias renováveis e aponta que, em 2015, a indústria do segmento foi responsável por empregar mundialmente mais de 8,1 milhões de pessoas. Ou seja, um aumento de 5\% ou 1,3 milhões a mais de trabalhadores em relação ao ano anterior, o que denota que as renováveis seguem uma tendência de alta contrária à de outros nichos do setor energético.

De acordo com Adnan Z. Amin, diretor geral da IRENA, tal aumento tem sido impulsionado pela queda nos custos de tecnologia das energias renováveis e por políticas públicas energéticas mais favoráveis. "Nossa expectativa é que essa tendência continue à medida que as renováveis se provem cada vez mais viáveis economicamente e os países se movimentem para alcançar seus objetivos climáticos estabelecidos em Paris”, afirma Amin.

Conforme foi destacado existe um grande desafio a ser vencido, fortalecer a matriz energética nacional, incentivar as ações e políticas relacionadas com eficiência energética, 
garantindo assim uma segurança energética e a inserção de novas tecnologias principalmente as de baixo carbono, para isso, cada vez mais temos que investir em qualificação e especialização, para que não ocorram, riscos de “apagão" de mão-de-obra, e também ao mesmo tempo a perda da confiabilidade dos sistemas por falha ou despreparo dos instaladores, figura 6 , e demais profissionais envolvidos.

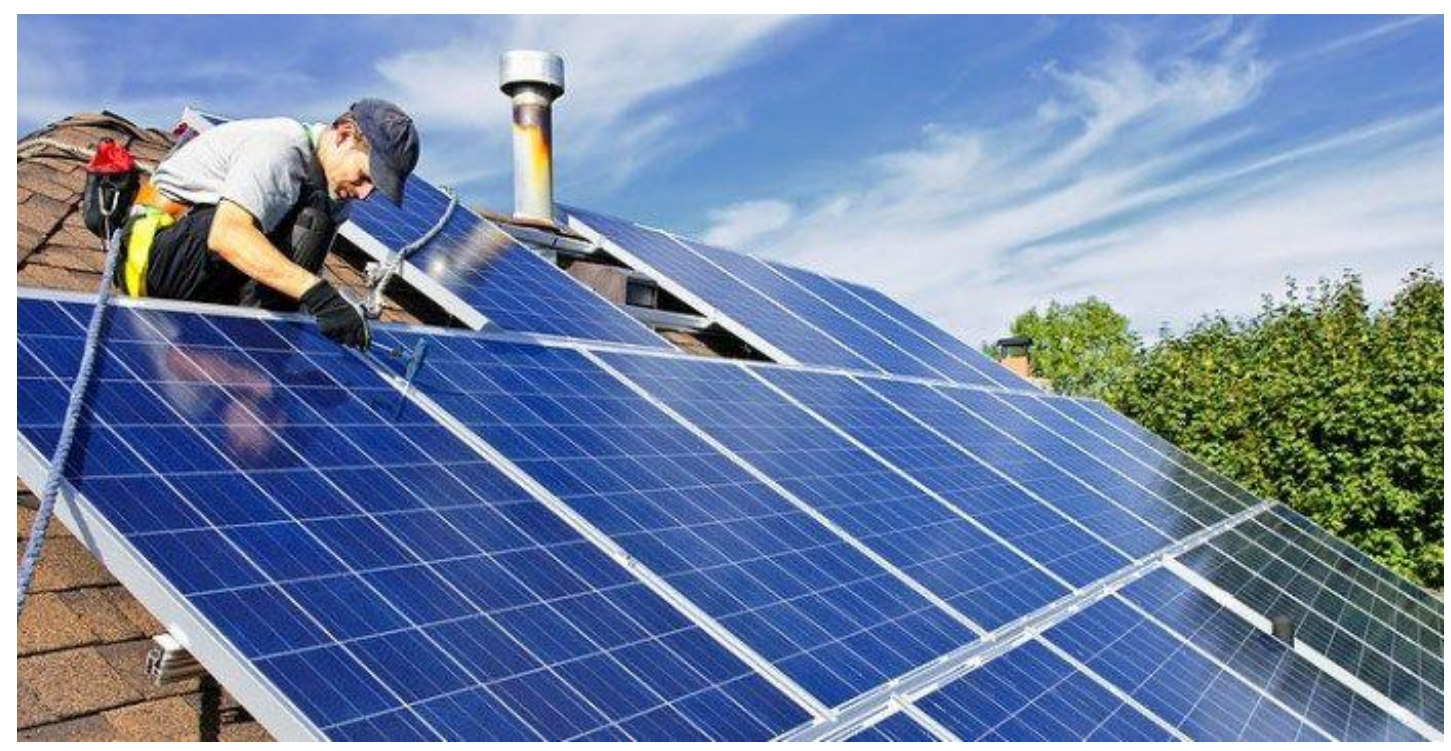

Figura 6. Profissional de Energias Renováveis

Fonte: Portal Energia, 2016.

Vale ressaltar o importante papel das instituições tradicionais de formação profissional, o que recai a maior responsabilidade nas iniciativas e que são as protagonistas nas ofertas e atendimentos destas novas demandas para o mercado, junto com estas ações, ainda se espera uma padronização de atendimento o que pode ser alcançado com um programa nacional de certificação para os profissionais de energias renováveis e eficiência energética.

\section{REFERÊNCIAS}

ABEE0LICA. Associação Brasileira de Energia Eólica. Disponível em: http://www.abeeolica.org.br/dadosabeeolica/ Acessado em: 22 janeiro de 2017.

ABESCO. Associação Brasileira das Empresas de Conservação de Energia. Disponível em http://www.abesco.com.br/associados/.Acessado Acessado em: 22 dezembro de 2016 
ABSOLAR. Associação Brasileira de Energia Solar Fotovoltaica. Disponívelem: http://www.absolar.org.br/projetos.html/ Acessado em: 22 janeiro de 2017

ANEEL. 0 Programa de Eficiência Energética Regulado pela ANEEL e a Geração Distribuída Agência Nacional de Energia Elétrica. Brasília, Brasil: SPE,2015.

ANEEL. (2016a). Banco de Informações de Geração (BIG). Disponível em: http://www2.aneel.gov.br/aplicacoes/capacidadebrasil/capacidadebrasil.cfm. Acesso em: 30 de setembro de 2016.

ANEEL. (2016b). Matriz de energia elétrica. Disponível em:

http://www2.aneel.gov.br/aplicacoes/capacidadebrasil/0peracaoCapacidadeBrasil.cfm. Acesso em: 30 de setembro de 2016.

BEN. (2015a). Balanço Energético Nacional 2015: relatório-síntese com ano-base 2014. Disponível em:https://ben.epe.gov.br/downloads/S\%C3\%ADntese\%20do\%20Relat\%C3\%B3rio\%20Final 2015 Web.pdf . Acesso em: 29 de setembro de 2016.

BEN. (2015b). Relatório final do Balanço Energético Nacional. Disponível em:

https://ben.epe.gov.br/BENRelatorioFinal.aspx?anoColeta=20158anoFimColeta=2014. Acesso em: $15 \mathrm{de}$ outubro de 2016

Empresa de Pesquisa Energética. Consumo de Energia no Brasil. Rio de Janeiro, Brasil: EPE, 2014.

GIZ. Estudo prospectivo sobre dimensionamento de mercado e demanda futurade mão de obra qualificada em áreas de fontes de energias alternativas renováveis e eficiência energética.Rio de Janeiro, Brasil: GIZ, 2013.

IRENA. International Renewable Energy Agency. Disponível em:http://www.irena.org/home/index.aspx?PriMenuID=12\&mnu=Pri Acesso em: 15 de outubro de 2016.

Ministério de Minas e Energia. Plano Nacional de eficiência energética: Premissas e Diretrizes Básicas. Brasília, Brasil: MME, 2011.

PORTAL DA ENERGIA. Energia Renovável Disponivel em: http:// www.portal-energia.com / Acessado em 29 de abril de 2017.

Secretaria de Energia. Balanço energético do estado de São Paulo 2015, Ano-Base: 2014. São Paulo: Secretaria de Energia, 2015.

Secretaria de Planejamento e Desenvolvimento Energético. Plano Nacional de Eficiência Energética. Brasília, Brasil: SPDE, 2015.

SENAI. Serviço Nacional de Aprendizagem Industrial. Plano de Negócios Instituto SENAI de Tecnologia Energia. São Paulo,Brasil: SENAI, 2015. 
SENAI. Serviço Nacional de Aprendizagem Industrial. Disponível em: http://www.sp.senai.br/senaisp/ Acessado em 28 Dezembro de 2016. 